\title{
Contracting for care - the construction of the farrier role in supporting horse owners to prevent laminitis
}

\author{
J. LYNDEN ${ }^{\dagger *}$ iD, J. OGDEN ${ }^{\dagger}$ and T. HOLLANDS* \\ †School of Psychology, Faculty of Health and Medical Sciences, University of Surrey, Guildford, Surrey, UK \\ \$School of Veterinary Medicine, Faculty of Health and Medical Sciences, University of Surrey, Guildford, Surrey, UK. \\ ${ }^{*}$ Correspondence email: jenny.lynden@surrey.ac.uk; Received: 27.07.17; Accepted: 31.03.18
}

\begin{abstract}
Summary
Background: Emerging research highlights how, due to demographic changes in horse owner populations in Western societies, complex owner-horse relationships are leading to inappropriate horse care, including overnutrition, which in turn can lead to laminitis. Farriers, due to their regular visits, may be in a position to support owners in dealing with this problem.

Objectives: This study explored whether UK farriers have a role in working with horse owners to support horse welfare and prevent laminitis.

Study design: Grounded theory analysis, a qualitative methodology.

Methods: Semi-structured interviews were conducted with 12 farriers and 11 horse owners. The interviews were transcribed verbatim and systematically analysed, using an inductive coding approach.

Results: The analysis of the farrier and horse owner interview data revealed farriers and horse owners undertake a contracting process leading to either a task-focussed or holistic care-focussed approach. Either approach can be satisfactory, but the evidence from this study suggests that when horses are at risk of laminitis, a task-focussed approach misses important opportunities to prevent it.

Main limitations: This analysis, based on a small sample of participants, was not able to identify the frequency of farriers or horse owners orientating towards different approaches in a way that can be generalised to a wider population. However, the power of grounded theory lies in its inductive design to develop new theory, which can be subsequently tested.

Conclusions: Farriers are in a perfect position to support horse owners to prevent laminitis through providing feedback, guidance and advice. However, not all farriers adopt this role and it is not necessary in all contexts. The evidence presented in this study has implications for equine veterinarians and welfare officers in educating horse owners about the value of holistic care-focussed farriery.
\end{abstract}

Keywords: horse; farriers; laminitis prevention; role theory; qualitative research

\section{Introduction}

Changes in the demographic profile of horse owners in Western society has resulted in serious concerns about the increase of equine obesity and associated disorders such as insulin resistance and equine metabolic syndrome, leading to increased risk of laminitis [1]. In Great Britain, it is estimated that $56.7 \%$ of horses are kept for pleasure and $12.8 \%$ retired, with the vast majority being cared for by their owner $(75 \%)$, many of whom are new to ownership, and with a large proportion being kept on own premises (37.2\%) [2]. This has important implications for equine welfare, not least because in a recent study, $60 \%$ of participants identified their horses as being an important 'social contact' and $47 \%$ stated that their horse was like a partner or child to them [3]. These types of complex human-horse relationships, which often involve affection and attachment, may result in nurturing-type behaviours, such as overfeeding [4]

In addition to 'nurturing-type' behaviour, it is also known that many owners are unsure about appropriate nutrition for their horse. In a survey involving 67 participants recruited during a visit to a large animal hospital in New England, $96 \%$ of participants reported feeding concentrate at least once per day to their horse despite the majority of horses in the study not being used for intensive activity. This suggests that owners do not understand equine nutrition and overestimate equine workload [1]. Moreover, a high proportion (69\%) modified diets or used dietary supplements to manage medical or behavioural conditions [5]. Interestingly, in another study, conducted with 300 yard managers in the UK and including riding schools, $49 \%$ reported increasing turnout time and $60 \%$ increasing the amount of hay, and therefore nutritional intake, as

This is an open access article under the terms of the Creative Commons Attribution License, which permits use, distribution and reproduction in any medium, provided the original work is properly cited. effective management solutions for stereotypic behaviour in horses [6]. This may, in part, explain why in a survey conducted in Great Britain, involving 873 participants, nearly $50 \%$ of horses were reported by owners as being turned out on pasture for $24 \mathrm{~h}$ per day during the summer [2]. This has important implications for horse obesity. In a study which measured the prevalence of obesity for domestic horses $(n=96)$ with access to pasture for at least six hours per day in North Somerset, obesity levels were BCS 7 or higher and rose significantly from $27.08 \%$ at the end of winter to $35.41 \%$ during summer $(\mathrm{P}<0.001)$ in line with grass availability. Recent research shows that only a minority of owners are able to correctly identify horse weight, and accurately assess body condition score [7].

Given the evidential link between poor nutrition and an escalation in disorders associated with obesity there is clearly a need to understand if and where owners seek information and guidance regarding equine nutrition. In a survey involving 930 horse owners living in Australia, 89\% identified horse health, $47 \%$ keeping or housing their horses and $42 \%$ pasture management and land keeping, especially relevant to the prevention and management of laminitis, as the most important issues for them. When asked what could address their concerns, 29\% suggested education and training and $19 \%$ better information and communication [8].

However, owner stated preferences for support may not reflect their advice-seeking or -uptake behaviour. For example, a survey of 536 Queensland owners who owned 2873 horses found stark differences between owners' awareness of signs of disease (including changes in weight) in older horses (>15 years) with the instance of consulted diseases. While $80 \%$ of horses were reported by owners as having indications of clinical signs of disease, only $35 \%$ of these were reported to have been diagnosed by a veterinary clinician [9]. In terms of accessing nutrition advice, a study conducted in New Jersey with 700 equine property owners, found $45 \%$ did not seek professional advice with regard to nutrition and $15 \%$ reporting no dietary plan at all. Where professional advice was sought, 
$20.5 \%$ asked veterinarians, 3\% nutritionists and $14.5 \%$ local feeding stores [10]. In terms of preferred sources of information, these findings correspond with a recent study in the USA where 55\% of the 74 veterinary surveyed considered equine nutrition to be 'very important' in their practice, with $78 \%$ reporting that they provided advice, particularly during routine health visits [11]. This evidence corresponds to the results of an online survey, involving 1326 leisure owners in the UK in which participants identified veterinarians, as well as farriers as the most common source of information regarding health and nutrition compared to other sources such as books and magazines [12]. However, this study did not distinguish between professional group, veterinarians or farriers, to which healthcare issues were directed. In contrast, in a study with Dutch owners, where this distinction was made, $69.6 \%$ of Dutch owners reported asking their farrier for information on horse care and health issues, which represented the second most important source of information, after the veterinarian [3]. As horse obesity and associated health risks remain a significant problem, and given the very low uptake and engagement of nutritional advice by owners, sources of support for owners need to be better understood [1].

Farriers may have a role in supporting owners to prevent laminitis, but as yet, no empirical research has been conducted into whether farriers take up this role and how it is enacted. While farriery training in the UK, involving a 4-year apprenticeship with an approved training farrier, as well as attending one of the three training colleges, does incorporate equine health and knowledge of causes of laminitis it does not explicitly include communication or interpersonal skills training. While the Farrier's Guide to Professional Conduct (2014) states 'good communication skills in professional and support staff are essential to good farriery practice', it is not until Fellowship level that this skill is formally examined by farriers demonstrating the skills of complex information giving. This is surprising as the importance of team working and communication skills between veterinarians, farriers and owners in managing positive outcomes for both acute and chronic laminitis has been identified [13].

The aim of this qualitative study was to identify how farriers perceive their roles in working with owners to prevent laminitis. The study draws upon role theory which understands the way in which roles are constructed through day-to-day interactions [14]. Role enactment requires the identification of selfhood through performance which anticipates and responds to others' behaviour. In this way, the performance of a professional role is constructed through the meaning attributed to it within social contexts. It is through the intersection between individual meanings attributed to professional roles and the social context in which roles are performed, that patterns of 'enactment' become normalised and routine $[15,16]$. Therefore, in order to understand the farrier's role, it is crucial to understand the meaning attributed to it by farriers as well as owners' perceptions of their interactions with farriers.

\section{Materials and methods}

\section{Design}

To understand how farriers interpret and make sense of their role in working with owners, a qualitative methodology is essential. As discussed by Christley and Perkins [17] qualitative approaches, appropriately applied, are robust in identifying meaning making which underpins behaviour. A grounded theory research method, particularly useful when studying a topic not yet researched [18], was used to explore farrier and horse owner understanding of the farrier's role. A set of rigorous analytic procedures, as outlined below, were applied systematically to produce a theoretical framework. This study is complex and can be reported in several ways, but this report will focus on the roles that farriers and owners co-create, explain how farriers and owners interact and what happens when there is a mismatch between farrier and horse-owner expectations regarding the farrier's role.

\section{Participants}

The study involved both farriers and owners. Data were collected opportunistically through the researcher's and associates' professional networks, using a purposive sampling technique aimed at recruiting farriers with as diverse a range of experience as possible. For example, farriers' qualifications ranged from Diploma (required to register and practice as a farrier) to Fellowship (equivalent to postgraduate training) levels with the Worshipful Company of Farriers. Additionally, farriers recruited to the study lived and worked across England, Scotland and Wales, and engaged in both specialist (e.g. remedial) and non-specialist farriery work. Of the 12 participants, 2 were female and participant ages ranged from 21 to 70 years.

It was clear from analysis of the farrier interviews that a key concern of farriers was (i) the context in which they worked and (ii) that owners were active in the creation of these contexts in very complex ways. This impacted on the farrier's role in working with owners. As theory generation follows an inductive approach, that is as the theory develops as gaps in the theory become evident, a 'theoretical sampling' technique was used seeking data to develop concepts to fill those gaps [19]. This emergent theory clearly required data from horse owners and hence a second stage of interviewing was conducted.

Owners who had experienced caring for horses with laminitis or who owned horses at risk of laminitis i.e. horses diagnosed with pituitary pars intermedia dysfunction (PPID) or equine metabolic syndrome (EMS) were recruited opportunistically to the study through the researcher's and associates' networks. Eleven owners with diverse backgrounds and experience were interviewed. The participants included owners with very limited experience, as well as those with a long-standing background and advanced horse care knowledge. Some participants kept horses to compete at affiliated levels, while others kept their horse for leisure, in light work or retired. All owners were female, aged between 21 and 70 years, kept at least one horse (with some participants keeping more than 5), including native, Thoroughbred and warmblood breeds. Participants' horses were kept: at 24/7 grass; or stabled with some turnout; and on DIY or assisted livery yards; or on owners' premises. Additionally, two owners were also yard managers and provided accounts not only of their own contexts in working with farriers, but also from their observations of different owners' interactions with farriers on their yards.

A 'cumulative' strategy, using data analysis at each stage, informed subsequent participant recruitment. The strategy included identifying 'negative cases', that is, cases that could test the conceptual analysis. This led to the recruitment of very diverse farrier and horse owner participant groups as outlined above. Farrier and horse owner participants were recruited until theoretical saturation was reached, that is when no further concepts or dimensions could be identified within the conceptual framework developed through analysis of the data [20]

\section{Procedure}

Participants gave their written consent to the audio-recording and transcription of a 1-h in-depth unstructured interview. While the interviewer was directed by a list of topics, the participants' interests and foci were explored in-depth. This approach is common for interviews in grounded theory, which avoids the use of structured interviews based on the researcher's understanding of what concerns participants and seeks to privilege the participants' perceptions and understandings [21].

Interviews with farriers were conducted through the mode preferred by the participant and depending upon their location. Eight interviews with farriers and all interviews with owners were conducted by telephone, the remaining four interviews with farriers were conducted face-to-face, in a variety of public locations. No differences were identified between the different modalities in terms of the richness and detail of the accounts given. The interviews with farriers began by asking them to give an outline of their training and working background, before exploring their perceptions about the farrier's role and experiences in supporting owners to prevent laminitis. The interviews with owners began by asking them to give an outline of their experience of owning horses (including the number and types of horses they had owned) as well as their experience of horse management (including number of years' experience and background with horses). Owners were asked if they believed the farrier had a role in supporting owners to prevent laminitis, and then asked to describe their experiences of working with farriers. All interviews were transcribed verbatim to include all spoken words, but not para-linguistic features such as pauses, changes in intonation, etc. This is because it was the content of 
the participant accounts that were being analysed, not the ways in which they were interacting with the researcher. The first two interviews with farriers and owners served as pilots to assess whether the interview strategy could yield data appropriate to answer the research question. The pilot and subsequent interviews were assessed as successfully eliciting a very diverse range of farrier and horse owner perceptions that supported the conceptual development.

A classic grounded theory analysis was conducted by the researcher because, as Glaser identifies, it has the capacity to develop a conceptual framework for understanding process and context [22]. Sensitising concepts for role enactment and development were used to frame but not restrict the analysis. Analysis used the procedures of the grounded theory research method developed by Glaser and Strauss [18]. Data from interviews with farriers was open coded using the constant comparison method which requires the comparison of incident to incident, incident to concept and concept to concept to emerge and develop categories. An incident is a sentence, word or paragraph identified within the transcripts of participants' accounts of their experiences, in this case, initially of farriers' experiences of working with owners. This method enabled the identification of key characteristics of the farrier's role and how these varied across contexts. As noted above, it was understood from farriers that there were key characteristics of their role that were dependent upon their interaction with horse owners. The emergent theory thus resulted in horse-owner interview data being analysed also, using the constant comparison method of incidents cited within horse owner interviews. During the analysis of farrier and horse owner experiences of working with each other, distinctions between farrier roles emerged where a number of key characteristics clustered around two typologies: 'holistically-' or 'technically-focussed' care, and similarly for horse owner characteristics which clustered around either a 'welfare-' or task-focussed' orientation towards the farriery process. The data were then analysed in terms of the consequences of differing farrier horse owner typologies based on farriers' and owners' experiences which identified four contexts of care, important for managing laminitis, its prevention and/or reoccurrence.

A coding framework was developed using NVivo, which included the identification and coding of concepts as well as the development of coding memos to track the analytic process and enhance its credibility [23]. While this strategy captured the number of incidents coded to each concept, as noted by Glaser and Strauss [18], it cannot be assumed that participants who have not discussed an experience, relevant to subsequent analysis, have not had that experience. Therefore, it is not possible to present frequency counts which are generalisable to the wider population. This limitation is considered in the discussion section. Coding sessions with the second (J.O.) and third (T.H.) authors throughout the analysis established the reliability of the analysis, essential for qualitative approaches.

An additional level of analysis involved the systematic checking of accounts in terms of whether the farrier's knowledge and understanding of laminitis and horse care issues was accurate. All instances of farrier or owner reports of information exchange were coded. This data was reviewed with the third author (T.H.), a nutritionist with expertise in hoof care. The third author confirmed that farriers' knowledge of laminitis was accurate, and that the advice and guidance they gave owners was appropriate. For example, farriers did not give advice about nutrition, but focused on feeding management (e.g. restricting grazing where horses were obese) and encouraging owners to seek nutritional advice from nutritionists and/or veterinarians.

\section{Results}

The analysis of the farrier and horse owner interview data revealed distinctive dimensions for farrier roles that were either more technically or holistically focussed. Farrier roles were actively constructed by farriers adopting a wide range of practices, but also by owners' differing expectations of a welfare-focus within the farriery process. This led to a very complex contracting process that has serious implications for the prevention of laminitis. Participants' data were analysed for associations with gender, age, etc., but none were found. This could be because these categories are not relevant for the processes reported here, or because of the small sample size.

\section{Farrier roles}

Relationship with owner: Farriers working holistically valued and expected to develop long-standing relationships with owners, often maintained over decades, characterised by mutual rapport and trust. These relationships were described as pivotal in understanding the wider context of care and horse management, as well as being able to provide appropriate support, including emotional support during times of horse owner difficulty. These relationships facilitated continuity of care in which many farriers described strategies for building a picture of 'normal' functioning for each horse, sometimes through the use of photographic evidence, but more often than not through what they described as a 'sixsense' in working with each horse.

FRO02: So every time I pick a foot up I run my hands down, just put it over the fetlock, dead simple and you think, whooh,...you develop just a sixth sense, you pick a leg up and you just touch it and you think this is odd.

When this approach was explored a few farriers talked about building a photographic memory of horses, including seasonal changes, based on changes in the horse's general condition, and involving monitoring the type and unevenness of wear on the shoe. This was described as a 'moving photograph' in their memories that enabled them to build a picture of 'normal' and 'abnormal' functioning in each horse.

FR003: Partly we are the one person that sees their animal regularly when the animal is well. So we see changes that may not be noticed by other individuals. But the other side of it is we also get a snapshot...We are working on a photographic instance... over the year [which] hopefully comes up to a steady picture.

Nearly all farriers in this study identified the importance of being able to discuss these changes with owners in considering horse management issues, such as regulating weight, preventing laminitis and referring for early veterinary intervention before a crisis occurred. In contrast, very few farriers, who were more technically focussed did not necessarily seek to build a long-standing relationship with the owner, either because this was not seen as necessary or as part of the farrier role. This had important implications in some contexts, particularly when working with owners who were unable to recognise risk factors currently associated with laminitis.

OWR002: Unfortunately, my horse wasn't identified until he was actually properly in the throes of laminitis. But the more I look back on it, the more I think there were various signs that should have been alerted to us...l'd never had a laminitic horse before, and whether my farrier had dealt with a laminitic horse before, I don't know... We had a strange extra heel growth on what turned out to be his worst foot. [He] was a little bit pottery as he walked across the yard, and sure enough the following week he went through this, I can't stand up stage, leaning back on his heels, and that's when laminitis was diagnosed [by a vet].

For farriers working holistically, recognising the early signs to support the prevention of laminitis involved building relationships which extended to other relevant parties. For example, a few farriers identified their unique position to build relationships with yard managers to support a 'solutionsbased' approach for improving horse management practices.

FR012: ... talking about things that [owners] feel are beyond their control... This is where our role as farriers comes in... Backing them up can be very helpful. . It might be something as simple as explaining to the owner of the yard that the horse needs [to lose weight]... and is there any opportunity to reduce the size of paddocks... things like that.

Interestingly, two owners who also had yard management roles also identified the importance of the farrier in motivating owners and yard managers to make changes. This they described was because the farriers held a professional role which legitimised such feedback, and therefore the feedback was more likely to be taken seriously. 
Engagement with owner: The type of relationship formed with an owner seemed crucial in determining possibilities for engagement with welfarefocussed care. The majority of farriers in this study, who were working holistically, used communication strategies which were tailored to meet horse owner's level of education, competence and interest in horse management. Sometimes, as one male farrier reported, this meant being blunt.

FR003: And I said, "...just look out, you'll have to do something; that is screaming waiting for laminitis," absolutely hideous. And I said to her, "Right what's the plan?" Now we spent half an hour going through what was going to happen this week, on management, on diet, on the work.

However, the majority of farriers also reported incidents where they used humour to work with owners in acknowledging horse obesity.

FR009: ... the horse is putting weight on, and the next time I went the horse had a rug on, and I said, "I'm surprised you put a rug on it," and she said, "Oh it's just to keep the flies off"... [and I said] "Why don't you just put a fly sheet on? This horse is sweating here. Are you trying to put it in a steam bath to make it lose weight?" And she laughed and said, "I didn't want you to see it was fat".

Many farriers talked about the importance of using analogies to both support owner understanding about the implications of changes in their horses. As one female farrier highlighted, this could be matched to examples pertinent to an owner's experience.

FR003: Yeah, the classic one is, "He's always a bit pottery this time of year". "No he's always laminitic this time of year." And I'll use analogies along the lines of, "Well if you were out in your heels last night, you're sore today. If I tell you, you can't take your heels off, you've got to live in them, how are you going to feel? OK. Right, you're really sore now aren't you, okay. So he had his heels on. He's got to take them off but the damage is done, he's still sore".

Most farriers also talked about the importance of using communication strategies involving open-ended questions and listening techniques to engage owners in making changes.

FR012: So it's more about asking them questions and seeing what their responses are to those questions...So if you find they're offering lots of things that seem like excuses, then you know [there's] work to be done... So I find if I do that then I can engage them in a conversation that comes around to these issues and then that allows them to think... It's less likely they're going to get upset about it.

While all farriers talked about the importance of following up these strategies with information giving, two specifically cited the use of props and visual aids to support clients' understanding of complex physiology and aetiology.

FR011: [I have a] laminated foot in a jar of formaldehyde, so I can show owners. . .actually explain the internal structures of the foot a little bit. Some people don't even know there's a bone inside the foot, so when the vet is talking about rotation of the distal phalanx or something the owners haven't got a clue... Simplifying it getting them to hold the bone and look at it and describe it in a very simplified form.

Nearly all farriers working holistically reported providing information and support to owners on feeding management (e.g. restricting grazing and soaking hay where horses were overweight or obese) and increasing exercise. Additionally, farriers were reported as discussing evidence-based studies and new directions for preventing laminitis (e.g. early diagnosis of PPID). These types of conversations were reported as taking place when there were concerns and equally when there were not, as general information sharing strategies between farriers and owners. Farrier and horse owner accounts clearly identified the farrier's role as a 'conduit' for developments in research on laminitis and as a referral agent to veterinarians and nutritionists for specialist advice and guidance. In contrast, those farriers who were more technically focussed were more likely to engage in jovial interaction and general 'chit-chat' with owners. These interactions were not reported as involving a knowledge or information exchange.

Engagement with Continuous Professional Development: It is now a requirement that farriers in the UK, who have qualified since 2016, engage in at least 10 points of Continuous Professional Development (CPD) per year. However, farriers qualifying before this date are not obliged to do so unless they are approved training farriers working with apprentices. In this study, farriers working holistically reported engaging in regular CPD, irrespective of whether they were newly qualified, very experienced farriers, or holding associate or fellowship status with the Worshipful Company of Farriers. Nearly all farriers participated in regular CPD through attending workshops, on-going formal training, and reading research in farrier and professional journals. Nearly all farrier and owner participants identified differences between those farriers who did not engage in CPD with those who did.

FR012: ... [CPD] it's really important, not only as individuals, farriers need to establish the authority to provide information, provide guidance, but also collectively as an industry we need to establish the authority or do what we can to maintain that authority.

For farriers working holistically, regularly updating their knowledge and practice became an important part of credentialising that practice in order to support owners through an information exchange.

Team working: Those farriers working holistically focused on the importance of team and partnership working with other professionals, not least as it provided an opportunity for professional development. Farriers who worked more holistically and engaged in regular CPD stated they believed it was their role to engage in partnership working even when there were differences of opinion with veterinary practitioners.

FR009: Something we are not taught, working within a team. . .a vet might ask you for something, and you think well actually this is not applicable to this situation, this would be better...I have a great way of dealing with it...[I say] "I had some pretty poor results doing what you've just suggested," then, "you've obviously had success from it. So what l'd like you to do is come along and talk me through it. So can we meet and can you talk me through exactly what you want me to do?".

Most farriers also talked about the unique role in being able to provide detailed knowledge about a horse and any changes in its condition and health. They highlighted how this evidence base could be valuable for veterinarians when diagnosing and treating horses.

FR003: ... and a vet may come out and see the horse once a year hopefully no more because that means there's something going wrong and all they can see is that animal at that time. I will know how an animal feels. As horses I know how they stand, and if they're not standing well... why isn't it as comfortable? We are there constantly questioning, constantly noticing all these subtle changes that are the ones that are precursors to laminitis.

Nearly all owner participants reported that farriers working holistically shared their knowledge with veterinarians and were able to defend their judgements in the evident of a disagreement. This was valued by all owners as they wanted to see vet-farrier teamworking and problemsolving, which mutually respected both practitioners' expertise.

In summary, the analysis suggests that these dimensions of practice cluster around a dichotomous farrier role typology as illustrated in Figure 1.

\section{Horse owner characteristics}

Relationship with farrier: Owners had differing expectations of their farriers and this was reflected in the type of relationship they sought. For many owners, trust in their farrier had to be earned rather than assumed, 


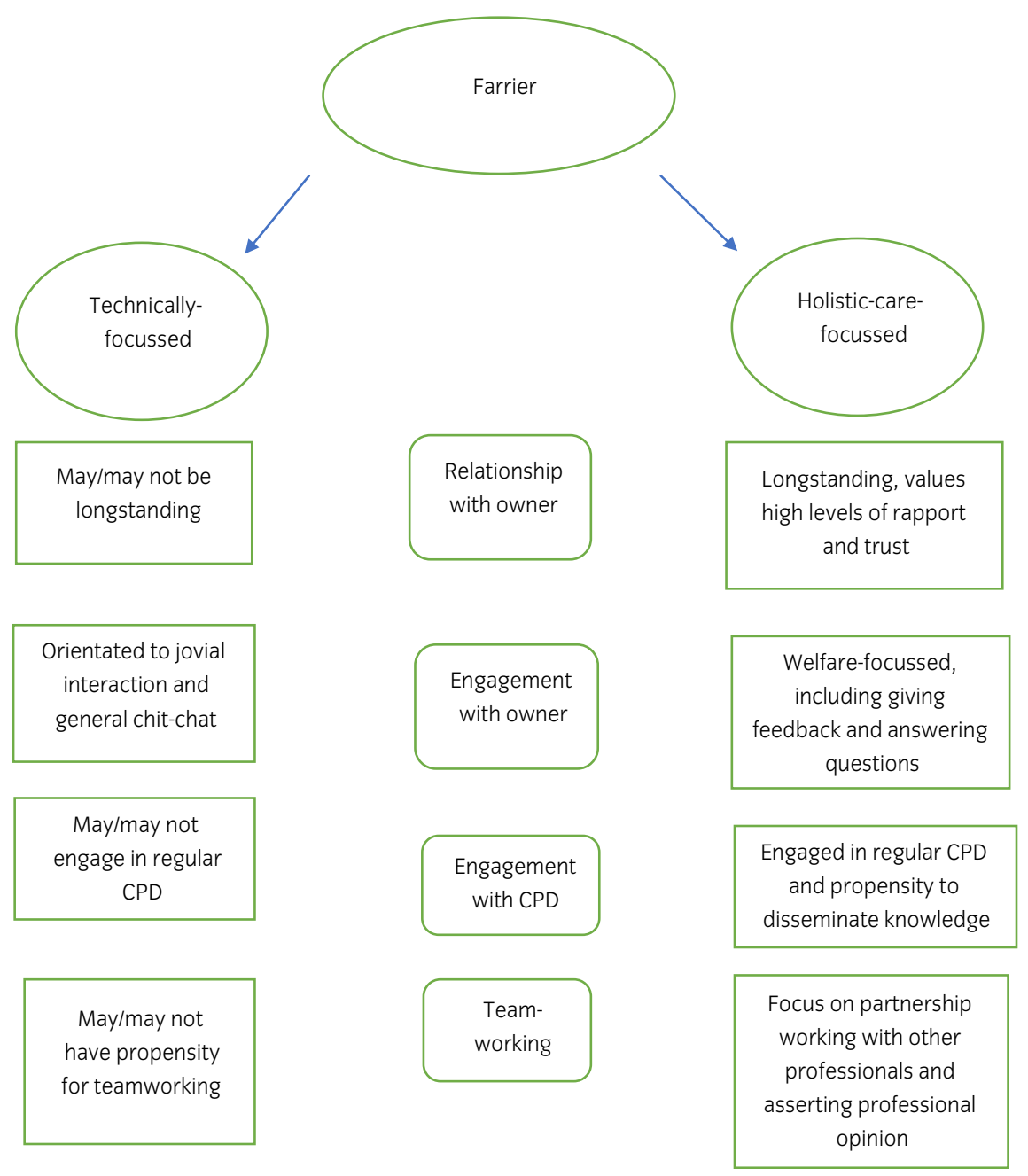

Fig 1: Conceptual analytic framework for farrier typology.

and while they would usually choose their farrier on the basis of recommendation, trust was built up through regular contact, observation of farrier's work and their interaction with the horse. Some owners identified the importance of continuity of care as integral to their horses' well-being which could be achieved through a welfare-focussed farriery process. Key to this was the farriers' ability and preparedness to give feedback about changes in condition and subclinical signs of disease. Interestingly, owners contrasted their experience of continuity within the farrier process with that of larger veterinary practices, where they would have no expectation of seeing the same vet. Many owners stated that this made their relationship with their farrier even more valuable to them in managing their horse's well-being because their farrier became a trusted source of support and advice-giving, relevant to their situation.

Very few owners did not recognise or need a long-standing relationship with their farrier, which involved regular or indeed any contact. Some farriers reported these types of owners as not recognising the importance of regular shoeing, believing it involved an unnecessary expense.

FR008: It's a massive problem because... I've had people ring up and say, "Can I have my horse shod?". You go and shoe it, and then they go, "When you gonna come back?" "In six weeks?" "No I'm not paying in six weeks."

These accounts were supported by two owners who also had yard management responsibilities, who similarly reported some owners refusing to book regular shoeing cycles.
Accounts of owner expectations of farriers, particularly in relation to keeping horses sound, varied considerably between owners. Those owners who did not seek long-standing relationships and continuity of care were more likely to assign responsibility for hoof condition and 'keeping shoes on' with the farrier. In contrast, owners who sought longstanding relationships with farriers, built on mutual trust, expected to share responsibility for managing hoof condition and discuss shoeing solutions.

Expectations of farrier: The two participants who were also yard managers, stated that some owners who did not recognise or require more holistic care as part of the farriery process were more likely to engage in jovial banter with farriers, or to be absent during farriery visits.

OWR010: One girl... didn't even used to be there when the farrier came. She would leave the horse in the stable and the farrier would come and shoe the horse. So as far as I know, apart from giving him some money, she had very little communication with her farrier because she was never there when a horse was shod.

This was contrasted sharply with the majority of owners, in this study, who were welfare-focussed and valued holistic-focussed care from their farrier.

OWR005: I have a farrier who is quite interested in horses and interested in the animal welfare side, and it's not just a job, 
because I have seen other farriers where it is just a job and they don't really bother saying much. If they are the farrier they are just shoeing that horse. Yes it's getting a bit fat, but they're just there to do that job.

For owners who valued holistic-focussed care from their farrier, the farriery process was an important part of monitoring the health and well-being of their horse. They actively sought feedback from their farrier to inform their horse management practices and valued personalised care through discussion and feedback.

OWR003: We've had a few different farriers throughout, but the one we have now, he makes it personal. He is there with that individual horse ... it will be a discussion, and he will ask for information from you and give you information.

Additionally, an owner who was also a yard manager stated the importance of the farrier in matching explanations for complex hoof morphology with owner understanding.

OWR005: Farriers I've had that I would say have been extremely supportive...they chat to the owner about what they're seeing. They draw little diagrams... and explain the foot in a way that the owner can understand. Perhaps basically initially, for more experienced owners there's going to be that little bit more.

Most owners highly valued their farrier's guidance regarding early signs and risks of laminitis, especially if they were new to horse ownership.

OWR011: I think going back to when we first took the pony... [My farrier] warned me then, he said, "He is a native-type breed. He is very prone to it. Be very very aware of how much grass you're giving him. What you're feeding him... [He] showed me where to look for fatty pouches and he would say, "Right monitor this...the fat on his neck" and that sort of thing. So he explained an awful lot about the sort of symptoms of Cushing's and things. I found that really helpful actually.

Additionally, for many owners, it was an opportunity to develop their knowledge and understanding of the farriery process and hoof health.

OWR010: I learned a huge amount from [my farrier] about horses' feet. He'd tell you all about the different types of shoeing. Why he thought this was better...it then prompts you to go onto the Internet and do your own sort of research

Relatedly many owners expected their farriers to engage in CPD events, and as already outlined enjoyed this knowledge being shared with them. They also expected to be able to question their farriers regarding the condition of their horses' hooves and why certain trimming/shoeing practices were being adopted. Owners were reassured when farriers could point to an evidence base, which informed their practice, although this could be based on anecdotal or practice-based evidence.

Accountability: Expectations of the farrier's role were reflected in differing levels of owner accountability when problems arose. Owners who were welfare-focussed expected to engage in joint problem-solving strategies with farriers and other professionals.

OWR005. . .but I do strongly believe an owner's responsibility is to keep themselves informed on horse care, and not just simply rely on calling one person out expecting them to work miracles. . . If you know perhaps what options are available then you can sort of ask the right questions of people. .

In contrast, as noted by an owner, also a yard manager, owners who were more task-focussed during the farriery process were reported as being more likely to assign blame for hoof-related problems to the farrier.

OWR005: Owners can be very critical of the farrier when shoes do come off and that might be because of the horse's movement slight shortening of stride in one leg or something like that. It might be an illness, subclinical illness, something like that... When a horse does go unsound, is it the farrier's fault?
This was supported by farrier accounts of the way different owners would engage with advice and their preparedness to take responsibility for changing horse management.

FR011: ... not an extreme case, a laminitic, it's now dead, they just wouldn't change, they wouldn't change the management. I think they were probably more convinced it was farrier-related than anything she was doing.

In summary, the analysis suggests that horse owner characteristics cluster around a dichotomous horse owner typology as illustrated in Figure 2.

\section{Contracting for care}

Throughout the interviews with farrier and horse owner participants, it was clear that a contracting process was undertaken early in the farrier-horse owner relationship. This led to four farrier-owner contexts. Technically focussed farriers working with welfare-focussed owners and holistic-carefocussed farriers working with task-focussed owners led to dissatisfaction. Welfare-focussed owners talked about 'sacking' farriers who refused to engage with them in providing holistic care for their horses. Holistic carefocussed farriers working with task-focussed owners sought to encourage more 'welfare-focussed' behaviour, such as regular shoeing. When owners refused to change, most farriers talked about 'sacking' their clients.

FR008: ... the people that we shoe for, we'll only shoe their horses if they want their horses shod properly. I won't shoe for anyone. Like I could drop my prices, I could be $£ 50$ a set. . .but I don't want to, I want to shoe for the people that. . want to ask me questions. They want to ask me how their feet are looking. Is my horse overweight?

Holistic care-focussed farriers working with welfare-focussed owners were active in supporting horse welfare, including exchanging information to recognise subclinical signs to prevent laminitis. There were many examples from farrier and horse owner interviews where it was believed laminitis or its reoccurrence had been prevented through this type of interaction.

The fourth and most interesting context concerned technically focussed farriers being matched with task-focussed owners. For some, this was an effective relationship, where farriers were either competent/expert practitioners, horses resilient to laminitis or owners had significant knowledge and skill in managing their horses' welfare. Problems occurred when owners, often novice owners, were unable to recognise risk factors for laminitis, such as obesity, and were engaging technically focussed farriers who did not orientate towards a holistic care focus, such as warning owners about the risks of equine obesity. Three owner participants, with horses at risk of laminitis, who did not orientate towards a welfare focus within the farriery process initially because they did not understand the potential of the farrier role's in supporting them, reported subsequent diagnosis of laminitis. Interestingly, these owners, often due to engaging a different farrier to undertake remedial farriery, reported becoming aware of the importance of the farrier's role in providing more holistic care and support thereafter.

OWR005: A lot of people are happy with their farrier as long as the shoes are going on and they don't come off... but I don't think some realise just how much their farrier can do to help their horse. . .'ve changed farriers a couple of times because my horses had needed a more experienced farrier in order to deal, for instance, with laminitis...

This grounded theory analysis has highlighted the complexities of a contracting process which served to construct different farrier roles. As shown above, this has implications for veterinary practitioners, particularly in supporting novice owners with horses at risk, in preventing laminitis.

\section{Discussion}

The current study has demonstrated complex interactions which contrast farrier roles, and the implications for equine welfare with regard to laminitis prevention. The grounded theory analysis, drawing on concepts from role theory, has highlighted how professional roles are mutually created 


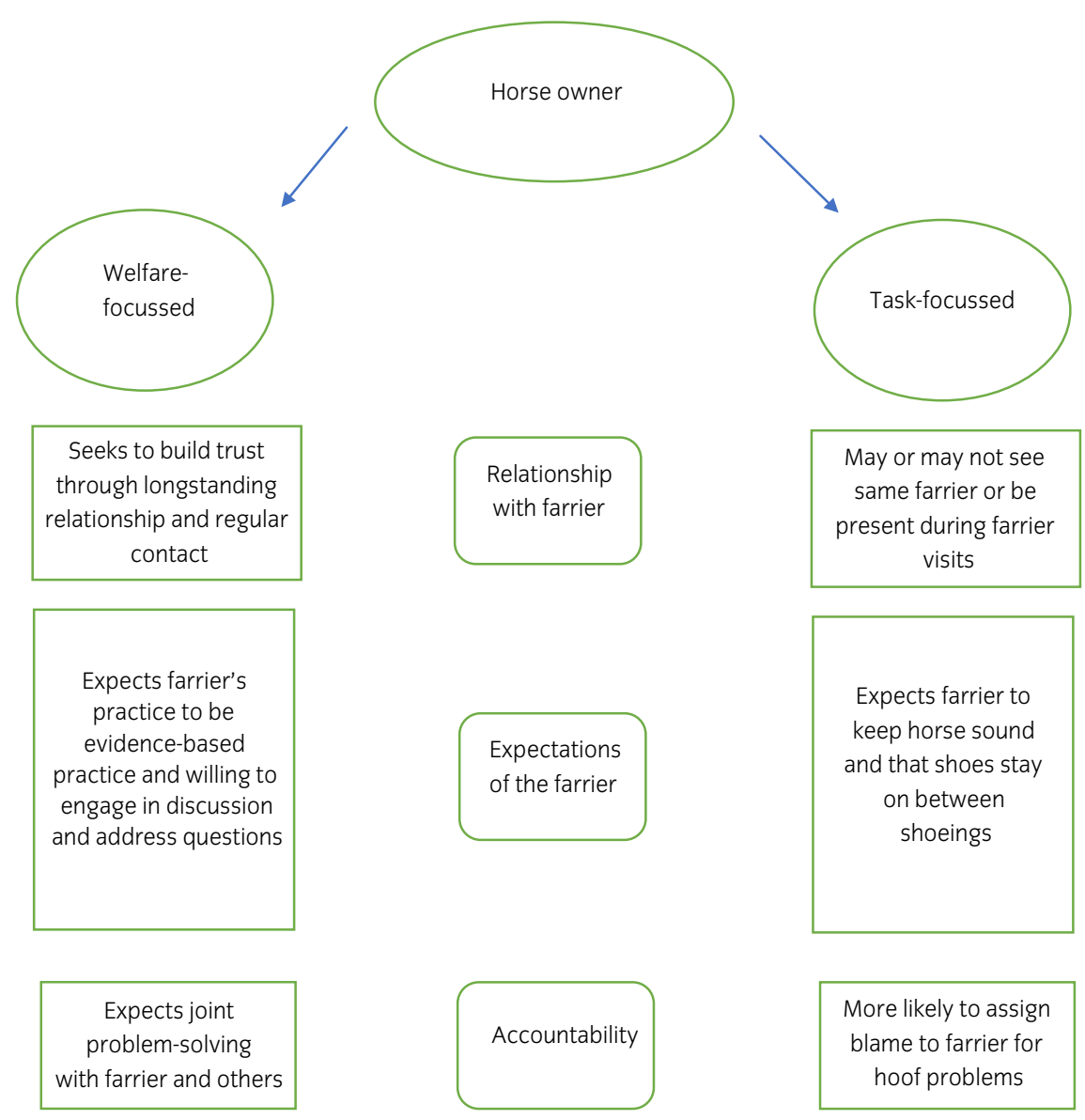

Fig 2: Conceptual analytic framework for horse owner typology.

through interaction, and that role enactment is contingent upon context. In this case matching of farrier and horse owner propensities for holistic care focussed or task-focussed care during the farriery process can have serious implications for the prevention of laminitis in horses. This is the first study which highlights the importance of farriers enacting a holistic role in which they make every contact count in supporting the welfare of horses. This has important implications for equine welfare given that, as discussed in the introduction, there have been significant changes in the demographic profile of horse owners with associated risks of overfeeding, incorrectly identifying body condition and complex advice-seeking anduptake behaviour. These are likely to be the reasons why, despite a substantive increase in information and guidance now available to owners, equine obesity and the associate risks of laminitis remain a significant problem.

The analysis presents evidence of how holistic care-focused farriers place an emphasis on building long-standing trusting working relationships. It is this approach that enables them to provide continuity of care, using a complex evidence base to inform their understanding of each horse and its owner. This understanding informs strategies to support owners. Not least, this is because farriers can recognise the owner's preparedness to change and then make every contact count in supporting that change through regular visits.

These findings can be compared with equine veterinary practice. There is extensive case study evidence on the importance of working empathetically with owners to help them understand the implications of laminitis, treatment and care plans [24]. Additionally, in small animal practice, there is case study evidence for practitioners using the transtheoretical model of change to develop partnership working with owners in supporting, for example, changes to feeding management [25]. The transtheoretical model of change recognises that individuals can be at different stages in their preparedness to change and that strategies, interventions and education must be appropriately matched to each stage if they are to be effective [26]. Research is also currently being undertaken in vet-farmer interactions to prevent mastitis in cattle, drawing on the transtheoretical model of change and motivating interviewing strategies, which highlight the importance of veterinarians adopting a partnership role with clients to provide important opportunities to gain knowledge and understanding of individual circumstances which can support strategies for client behaviour change [27].

There have been no randomised controlled trials in equine veterinary contexts to assess the efficacy of the transtheoretical model of change and motivating interviewing approaches in partnership working with owners. In terms of the prevention of laminitis, such as regular monitoring of horse condition and changes in hoof condition, it could be argued that the farrier is in the best position to develop partnerships with owners as they see them more frequently and for longer periods of time than a vet during periods of 'wellness'. The current research, therefore, makes a contribution to the understanding of how partnership working in an equine care setting has evolved through farriers working holistically, and that farriers do indeed have a role in supporting partnership working with clients to prevent laminitis.

As the current study highlights, the contexts in which farriers work are complex. An understanding of these contexts and the farrier-horse owner contracting process has important implications for equine veterinary practice. As presented in the results section, a more task-focussed approach does not provide opportunities to prevent laminitis where horses are at risk, owners do not have the knowledge needed to manage horse condition or recognise signs of PPID/EMS and are not aware of the possibility for holistic care-focussed farriery support. Using the evidence presented in the current study, equine veterinarians and welfare officers 
are uniquely placed to guide owners, in this position, to integrate a welfare-focus when working with their farriers. This could include, for example, encouraging owners to ask their farriers questions about hoof condition and to discuss related concerns. There is also an opportunity now to conduct a randomised controlled trial, involving farrier training, to identify the effectiveness of farriers making every contact count in supporting the management of horse obesity and support the prevention of laminitis.

The current study also has implications for veterinary practitioners in that it provides important insights into farrier roles and enactment of those roles which impact on vet-farrier teamworking. It was clear from the interviews that owners highly value a team approach, where both vet and farrier knowledge and expertise is recognised involving joint decisionmaking processes. The current study highlights holistic care-focussed farriery practice which involves farriers using complex communication skills to exchange information with owners. As the results demonstrated, farriers are using a range of techniques, similar to those used in transtheoretical model of change and motivating interviewing interventions, which encourage owners to reflect on their understanding and motivation to, for example, adhere to equine weight loss/maintenance plans. As Weiner argues, veterinary clinical interventions must take account of human factors which influence disease outcomes [28]. In this regard, it is critical to understand the client's individual circumstances, as well as clinical factors, which jointly inform the clinical intervention. The evidence from this study could be used to extend vet-farrier joint CPD events which facilitate a knowledge- and skills-exchange, sharing practices for developing partnership working with clients.

In evaluating grounded theory studies, Glaser and Strauss argue that studies should be assessed in terms of their credibility, plausibility and trustworthiness, and these standards should be applied to every stage of the research process [21]. Key to establishing these standards is the requirement that the theory is fitted to the data through an inductive analytic process which, while guided by sensitising concepts is not directed by them, thereby forcing the data to fit a pre-existing theoretical framework. In the present study, although guided by the concepts around role theory (role construction, enactment, conflict, etc.) these did not direct the analysis. The conceptual framework arose from the constant comparisons within and between each case to identify participants' experiences and concerns, and the contexts in which they operated. The plausibility of the initial concepts was tested by seeking variance across cases, including the recruitment of 'negative cases' (i.e. those that were unlikely to fit the developing framework). It was through this process that the complexities of the farrier and owner typologies, and the complexities of the contracting process fitted to the conceptual model. Only when no new conceptual categories or refinements to the dimensions of existing categories were possible, was theoretical saturation believed to have been achieved.

The reliability of the coding process was tested through coding sessions between the authors to check the credibility of interpretations. However, a qualitative approach using semi-structured interviews with a small sample and grounded theory analysis cannot identify the frequency of farriers or owners orientating towards holistic- and welfare-focussed care, and whether these relate to variables such as gender and age, or in a way that can be generalised to a wider population using probabilistic statistical procedures. The power of grounded theory lies in its design to develop new theory, through inductive analysis, which can be subsequently tested using a quantitative method. For example, a survey design, recruiting a large number of farrier and horse owner participants, could test how the characteristics identified in the current study, as well as demographic variables such as gender or age, cluster around the farrier and horse owner typologies, and four contexts using a factorial design. Additionally, correlations between typologies and contexts with reported incidents of laminitis and its reoccurrence could be identified through an appropriate questionnaire design. Once relevant factors are identified, it could be adapted for use with other paraprofessional groups (such as equine dentists, physiotherapists, etc.) in identifying their role in supporting equine welfare vis-à-vis the extent to which this supports partnership working with veterinarians.

In conclusion, this study highlights the unique and valuable role farriers have working in partnership with owners and veterinarians to make every contact count in helping to prevent laminitis. It is clear that holistic care-focussed farrier interventions are guided by complex and sophisticated practices and communication skills. This insight provides a rich resource for veterinarians and welfare officers to support owners in considering opportunities for accessing welfare support within the farriery process. It also provides a rationale to further enhance farrier and veterinary training in understanding the potential of the farrier's role in partnership working with owners to prevent laminitis.

\section{Authors' declaration of interests}

No competing interests have been declared.

\section{Ethical animal research}

The study was approved by the University of Surrey Ethics Committee, which meets British Psychological Society and Veterinary ethical standards. All farrier and horse owner participants gave informed consent.

\section{Source of funding}

The research undertaken forms part of a self-funded PhD.

\section{Acknowledgements}

The authors would like to thank the farrier and horse owner participants for their interest in the study and their time in engaging with the in-depth interviews. We also want to thank the reviewers for their very constructive and supportive feedback on drafts of this paper.

\section{Authorship}

J. Lynden is a PhD candidate who conducted the research, planned and executed the study. She also authored the study materials, recruited participants and conducted, transcribed and analysed the interviews. In addition, she wrote the first draft of the paper and worked with the other authors comments/reviews. J. Ogden is J. Lynden's primary PhD supervisor and provided detailed guidance on the planning and design of the study from a psychological and methodological perspective. She supervised the research execution and checked the transcripts for accuracy and supported data analysis through coding and analytic sessions. T. Hollands is J. Lynden's secondary PhD supervisor and provided detailed guidance on the planning and design of the study from a veterinary perspective. She supported the recruitment of participants to the study and supported data analysis through coding and analytic sessions. Both J. Ogden and T. Hollands provided detailed feedback on drafts and approved for the final version of the manuscript.

\section{References}

1. Roberts, J.L. and Murray, J.-A. (2014) Equine nutrition in the United States: a review of perceptions and practices of horse owners and veterinarians. J. Equine. Vet. Sci. 34, 854-859.

2. Hotchkiss, J., Reid, S. and Christley, R. (2007) A survey of horse owners in Great Britain regarding horses in their care. Part 1: horse demographic characteristics and management. Equine Vet. J. 39, 294-300.

3. Visser, E.K. and Van Wijk-Jansen, E.E. (2012) Diversity in horse enthusiasts with respect to horse welfare: an explorative study. J. Vet. Behav. 7, 295-304.

4. Hollands, T., Ellis, J., Allen, D. and Salonen, L. (2009) An assessment of 2 visual methods of fat scoring in the equine to determine the most suitable for client recognition of obesity in their horses. In: Proceedings of the Congress of the British Equine Veterinary Association, EVJ Ltd, Fordham, Cambs. pp 247-248.

5. Hoffman, C.J., Costa, L.R. and Freeman, L.M. (2009) Survey of feeding practices, supplement use, and knowledge of equine nutrition among a subpopulation of horse owners in New England. J. Equine. Vet. Sci. 29, 719-724. 
6. McBride, S. and Long, L. (2001) Implications for welfare. Vet. Rec. 148, 799-802.

7. Morrison, P.K., Harris, P.A., Maltin, C.A., Grove-White, D., Barfoot, C.F. and Argo, C.M. (2017) Perceptions of obesity and management practices in a UK population of leisure-horse owners and managers. J. Equine. Vet. Sci. 53, 19-29.

8. Thompson, K. and Clarkson, L. (2016) Issues faced by horse owners in Australia: implications for vet-client communcation. Aust. Equine Vet. 36, 41-47.

9. McGowan, T., Pinchbeck, G., Phillips, C., Perkins, N., Hodgson, D. and McGowan, C. (2010) A survey of aged horses in Queensland, Australia. Part 2: clinical signs and owners' perceptions of health and welfare. Aust. Vet. J. 88, 465-471.

10. Westendorf, M.L., Puduri, V., Williams, C.A., Joshua, T. and Govindasamy, R. (2013) Dietary and manure management practices on equine farms in two New Jersey watersheds. J. Equine. Vet. Sci. 33, 601-606.

11. Roberts, J.L. and Murray, J.-A. (2013) Survey of equine nutrition: perceptions and practices of veterinarians in Georgia, USA. J. Equine. Vet. Sci. 33, 454-459.

12. Hockenhull, J. and Creighton, E. (2013) A brief note on the informationseeking behavior of UK leisure horse owners. J. Vet. Behav. 8, 106-110.

13. Orsini, J.A., Wrigley, J. and Riley, P. (2010) Home care for horses with chronic laminitis. Vet. Clin. N. Am.: Equine Pract. 26, 215-223.

14. Goffman, E. (1978) The Presentation of Self in Everyday Life, Harmondsworth, London.

15. Brookes, K., Davidson, P.M., Daly, J. and Halcomb, E.J. (2007) Role theory: a framework to investigate the community nurse role in contemporary health care systems. Contemp. Nurse 25, 146-155.
16. Hardy, M.E. and Conway, M.E. (1988) Role Theory: Perspectives for Health Professionals, Appleton \& Lange, Connecticut.

17. Christley, R. and Perkins, E. (2010) Researching hard to reach areas of knowledge: qualitative research in veterinary science. Equine Vet. J. 42, 285-286.

18. Glaser, B.G. (1998) Doing Grounded Theory: Issues and Discussions. Sociology Press, Mill Valley, CA.

19. Glaser, B.G. (2005) The Grounded Theory Perspective III: Theoretical Coding. Sociology Press, Mill Valley, CA.

20. Bryant, A. and Charmaz, K. (2007) The Sage Handbook of Grounded Theory, Sage, London.

21. Glaser, B.G. and Strauss, A. (1967) The Discovery of Grounded Theory. Aldine Transaction, New Jersey.

22. Glaser, B.G. (1978) Advances in the Methodology of Grounded Theory: Theoretical Sensitivity, Sociology Press, Mill Valley, CA.

23. Bazeley, P. and Jackson, K. (2013) Qualitative Data Analysis With NVivo, Sage Publications Limited, London.

24. Walsh, D.M. (2004) Laminitis: what to tell the owner. Clin. Tech. Equine Pract. 3, 83-87.

25. Churchill, J. (2010) Increase the success of weight loss programs by creating an environment for change. Compend. Contin. Educ. Vet. 32, E1.

26. Prochaska, J.O. and Velicer, W.F. (1997) The transtheoretical model of health behavior change. Am. J. Health Promot. 12, 38-48.

27. Bard, A. (2016) Inspiring change: what motivational interviewing can teach us about communicating herd health advice. Cattle Pract. 24, 109-110.

28. Weiner, S.J. (2004) From research evidence to context: the challenge of individualizing care. ACP J. Club 141, A11-A11. 